\title{
Numerical model for investigating seismic performance of Prestressed Hollow Concrete (PHC) piles with Fiber section element
}

\author{
Angga Fajar Setiawan ${ }^{1}$, Muhamad Fauzi Darmawan ${ }^{1}$, Sito Ismanti ${ }^{1}$, Mukhlis Sunarso ${ }^{2}$, Guntara Muria Adityawarman ${ }^{2}$ \\ ${ }^{1}$ Department of Civil and Enviromental Engineering, Universitas Gadjah Mada, Indonesia \\ ${ }^{2} \mathrm{PT}$ Wijaya Karya Beton, Indonesia
}

\begin{abstract}
In the medium to high seismic zone, prestressed hollow concrete (PHC) pile for structural foundation should be designed with elastic behavior due to low ductility and dissipated energy. However, some Indonesian practical engineer has chosen PHC pile for pile-supported slab viaduct (PSSV) with medium seismic moment-resisting frame concept in a high-risk earthquake zone. Therefore, some nonlinear numerical simulations of PSSV structure in medium to high seismic zone need to be conducted to investigate its seismic performance. In the initial stage, a numerical model for investigating the seismic performance of PHC pile under flexural test was conducted. By implementing an appropriate plastic hinge length of forced beam-column with hinge elements, the flexural behavior of PHC piles to be simulated under both monotonic and cyclic loading. The fiber section was adopted to accommodate non-linear behaviour of material in the PHC pile cross section. As the results, the skeleton curves, the sectional strain distributions, and the hysteresis curves have good agreement results compared with the experimental results. Furthermore, based on the equal damping ratio calculation of the hysteresis curve, the PHC pile only achieve low energy dissipation, though the ductility capacity around 3. Finally, this numerical model approach could be adopted in the non-linear simulation of PSSV structure under seismic load.
\end{abstract}

\section{Introduction}

\subsection{Background}

Several significant earthquakes occurred in some Indonesian region in last two decades. Indonesia located in ring of fire, contains about 13 segments of long belt subduction in South-West and North-East area with potential earthquake occurrence range 7,8 to $9,2 \mathrm{Mw}$ [1]. Also, there are 251 active faults stand up in almost of Indonesian main island, except Kalimantan Island with potential earthquake magnitude 6,0 up to $8,1 \mathrm{Mw}$ [1]. Under current earthquake occurrence, Lombok Earthquake $(7,0 \mathrm{Mw})$ occurred in August 2018 and killed 555 people. Then, in September 2018, Palu Earthquake (7,4 Mw) occurred with 2045 people killed [2]. Furthermore, Halmahera Earthquake (7,2 Mw) is the last significant earthquake have been occurred in July 2019, damaging hundreds of houses and killed 14 victims [3]. Therefore, development of high seismic performance of housing and infrastructure maybe one of survival keys during life in Indonesia.

Even though, development program of high seismic performance infrastructure has been started, some mistake or misunderstanding seismic design of structure concept was observed in Indonesia. A structural engineer [4] reviewed PHC pile-supported slab viaduct (PSSV), as illustrated in Fig. 1 with medium moment resisting concept. In their design, seismic force reduction factor (R) reach to five [4]. While, based on the Budek et al [5], elastic design concept should be adopted for a structural foundation with PCHP in medium to high seismic zone to avoid brittle failure behaviour under earthquake load. In the PSSV structural configuration, two brittle plastic hinge formation of PHC pile will arise, as illustrated in Fig. 2. Therefore, some non-linear numerical simulations of PSSV structure with PHC pile need to be conducted to investigate its seismic performance. Before those, numerical model calibration needs to be conducted by comparing with the experimental result from some predecessor researchers.

In this paper, to calibrate numerical model of $\mathrm{PHC}$ pile, three previous experimental of PHC pile under flexural monotonic and cyclic loading were simulated with OpenSees. OpenSees can be utilized to simulate and analyse the seismic response of structural and geotechnical system numerically [6]. Nonlinear finite element models were developed to analyse the seismic performance of the PHC pile with the force-based beamcolumn element with hinges. Also, fiber section with prestressing bars to be considered to accommodate the

\footnotetext{
* Corresponding author: angga.fajar.s@ugm.ac.id
} 
prestressed effect. Furthermore, appropriate plastic hinge length determined to achieve reasonable plasticity. The results obtained from the numerical analysis were compared to the result of the experiments in term of skeleton curves and hysteresis loops. The calibrated parameters of numerical model of PHC pile expected to be adopted for seismic performance investigation of the PSSV structural system. Moreover, with numerical analysis, hysterical damping energy expected to be quantified.

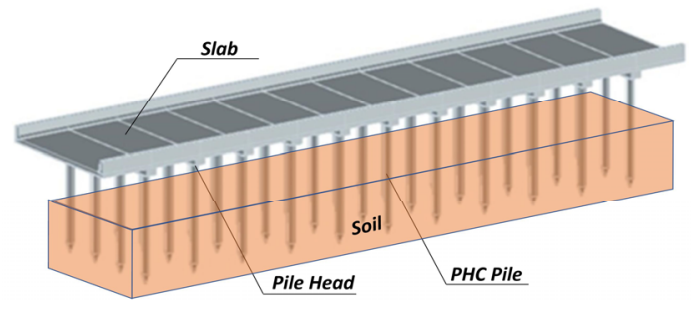

Fig. 1. Configuration of pile-supported slab viaduct.

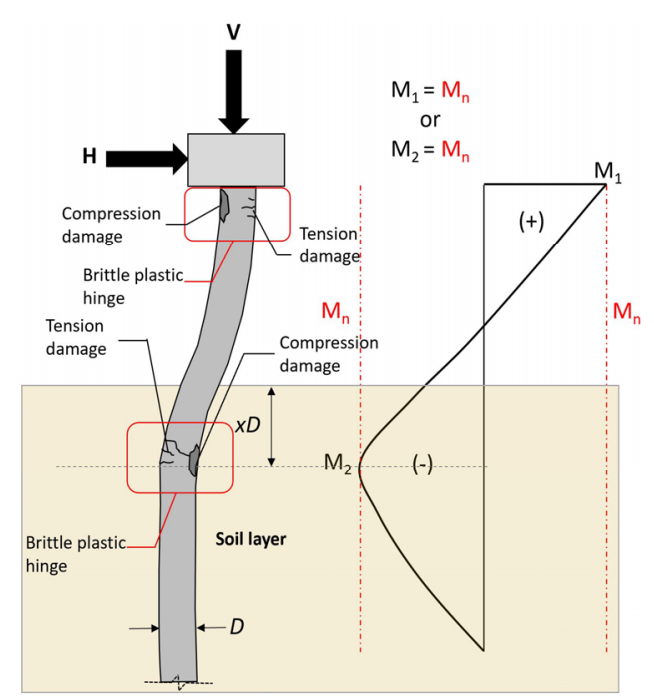

Fig. 2. Brittle plastic hinge mechanism of hanging PHC pile.

\section{Previous Experiment}

\subsection{Irawan et al (2016)}

Three specimens of six-meter length PHC piles were tested due to monotonic flexural loading to investigate the failure mechanism of a PHC pile [7]. The setting up of the experiment is shown in Fig. 3. The PHC piles section with $400 \mathrm{~mm}$ and $250 \mathrm{~mm}$ outside and inside diameter respectively can be seen in Fig. 4. The compressive concrete strength $\left(f_{c}^{\prime}\right)$ was $52 \mathrm{MPa}$. Ten pre-stressed steel (PC) bar with $7.1 \mathrm{~mm}$ diameter were used as longitudinal reinforcements of the PHC pile. The PC bar had 39,6 $\mathrm{mm}^{2}$ area. Based on the tension loading test, the PC bars had the average values of elastic modulus, yield stress and ultimate stress were 220,200 $\mathrm{MPa}, 1370 \mathrm{MPa}$ and $1424 \mathrm{MPa}$ respectively. The PC bar's initial strain at pre-stressing was $5,000 \mu \varepsilon$.

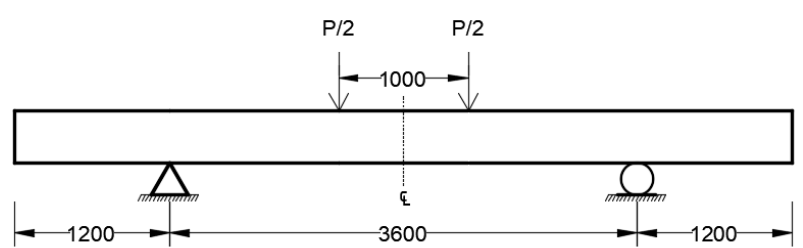

Fig. 3. Setting up of Irawan's et al experiment [7]

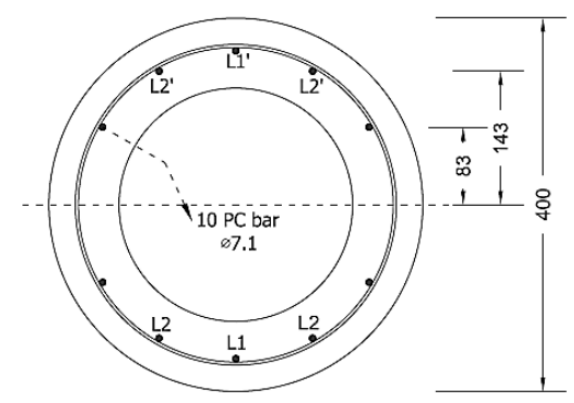

Fig. 4. PHC pile section cut of the Irawan's et al experiment [7]

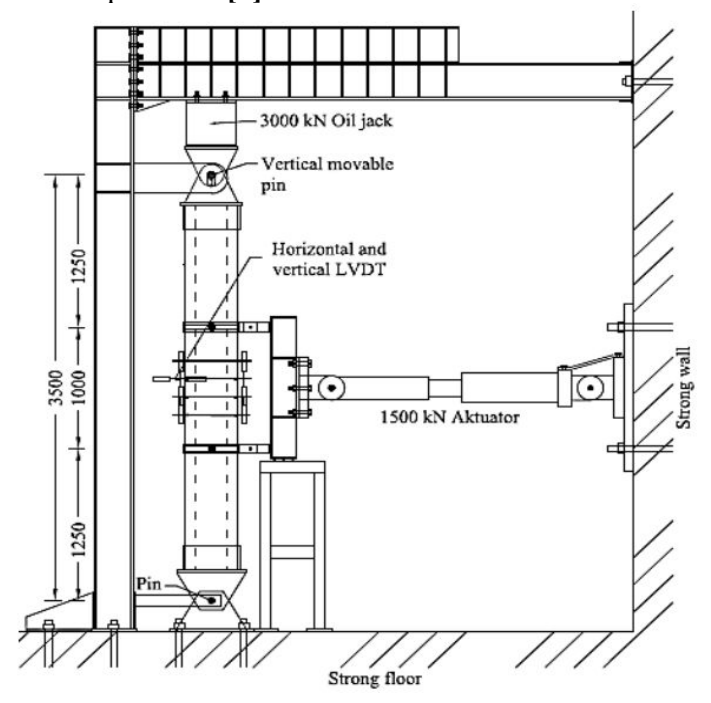

Fig. 5. Setting up of Irawan's et al experiment [8]

\subsection{Irawan et al (2018)}

Two PHC pile were tested by Irawan et al due to cyclic lateral loading: S-TB-1 and S-TB-3 [8]. Specimen S-TB1 dan S-TB-3 were axially loaded with 40 tons and 80 tons respectively. Shown in Fig.5 is the test setup schematic view of the experiment. Specimens had 400 $\mathrm{mm}$ outside diameter and $75 \mathrm{~mm}$ wall thickness. The pile's section detail is shown at Fig.6. The compressive concrete strength was $f_{c}{ }^{\prime}=54.4 \mathrm{MPa}$ at 28 days age testing. There was ten pre-stressed steel (PC) bar inside the pile. The yield and ultimate stress of the PC bar were $1387 \mathrm{MPa}$ and $1455 \mathrm{MPa}$ respectively. While the modulus elastic was 220,267 MPa. PC bars were subjected to $5,000 \mu \varepsilon$ tensile strain. 


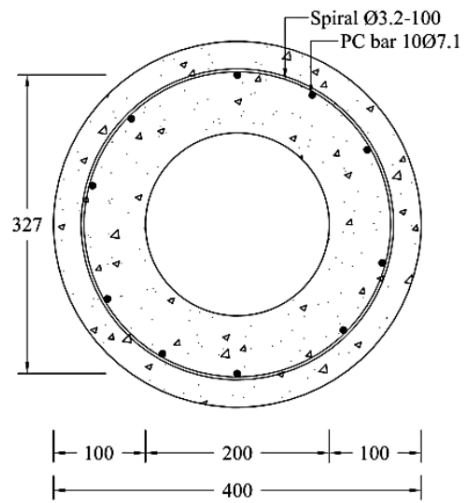

Fig. 6. PHC pile section cut of the Irawan's et al experiment [8]

\subsection{Taksinrote (2001)}

Ten specimens of pre-tensioned PHC high strength concrete piles were tested to investigate the seismic parameter of the piles under varying axial compression and cyclic lateral loads [9]. The PHC piles had $250 \mathrm{~mm}$ and $55 \mathrm{~mm}$ outside diameter and wall thickness respectively. The pile contained six PC bar with $50 \mathrm{~mm}^{2}$ cross-sectional area of each strand. The PC bars had $1395 \mathrm{MPa}$ yield strength, $1436 \mathrm{MPa}$ ultimate strength and $199100 \mathrm{MPa}$ Young's modulus. Each of PHC pile concrete had it own compressive strength. The section cut of the pile can be seen in Fig. 7 and Fig. 8 shows the test set up. LVDT 1 and LVDT 2 were placed for rotations measurement. LVDT 3 was used to measure the movement of the actuator support. LVDT 4, LVDT 5 and target were installed for strain measurements.

\section{Numerical Analysis under Monotonic Loading}

\subsection{Structure idealization}

PHC piles tested under monotonic loading by Irawan et al [7] were simulated and analysed numerically using OpenSees. The PHC pile specimen was idealized as a frame element in the 2D model with 3 degrees of freedom (DOF). The model consisted of eight nodes and six elements (one of them was dummy nodes). Nodes and elements tags can be seen in Fig.9. Node 3 and 4 had equal DOF with node 8 . Forced-based beam-column element with fiber section is applied to all elements of the model. Fiber, patch or layer can be utilized to model the fiber section in OpenSees. Each of them has uniaxial material, an area and local coordinate [10]. An example of fiber section for PHC pile modelling is shown in Fig. 10. Element 3 and 4 were defined with non-linear fiber section and the other elements with linear elastic fiber section. The non-linear fiber section consisted of a circular concrete patch and circular PC bar layer. The circular concrete patch was divided to 72 and 20 fibers in the circumferential direction and the radial direction respectively. Modified two-point Gauss-Radau integration was used to define the hinge region at the element ends and at $8 / 3$ the hinge length inside the element [11].

Budek et al conducted flexural test of four hollow prestressed piles with cyclic loading [12]. The actual plastic length obtained from the observation was in range $0.85 \mathrm{D}-1.45 \mathrm{D}$. The plastic hinge length of PHC Pile model idealization for Irawan's et al experiment was 560 $\mathrm{mm}(1,4 \mathrm{D})$, following the experimental of Budek et al [12].

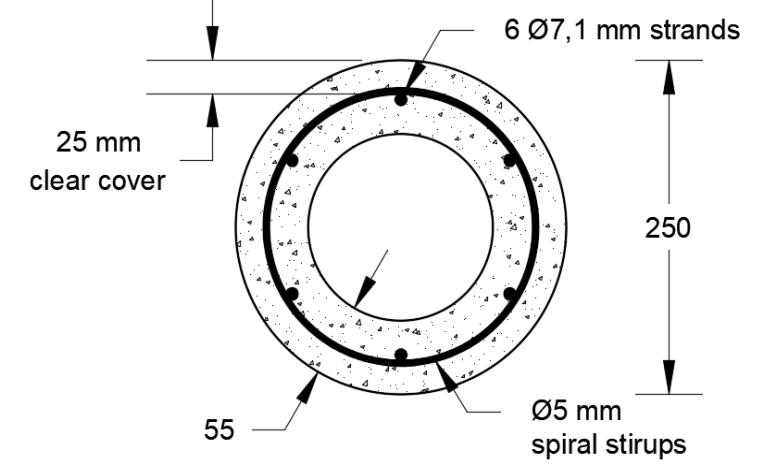

Fig. 7. PHC pile section cut of the Taksinrote's experiment [9]

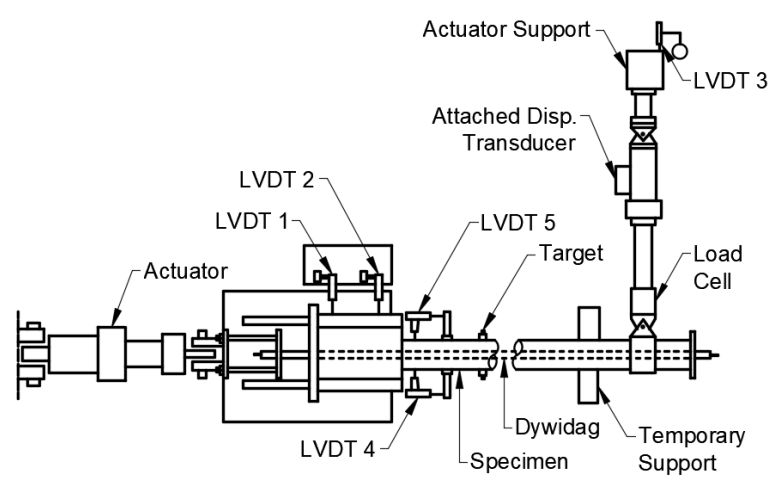

Fig. 8. Setting up of Taksinrote's experiment [9]

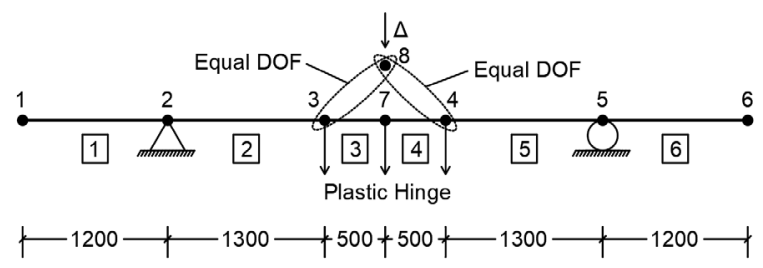

Fig. 9. PHC Pile model idealization for Irawan's et al experiment [7]

\subsection{Concrete material parameter}

Concrete 07 was implemented to model the concrete of the pile material of OpenSees adopts Chang and Mander's 1994 concrete model. It was an advanced rulebased model to simulate hysteretic of concrete both ordinary or high strength concrete [13]. The axial load should be on the section subjected to cyclic loading so that no problem occurs [14]. The input parameter of Concrete 07 material were concrete compressive strength $\left(f_{c}\right)$, concrete strain at maximum compressive strength $\left(\varepsilon_{c}\right)$, initial elastic modulus of the concrete $\left(E_{c}\right)$, tensile strength of concrete $\left(f_{t}\right)$, non-dimensional term that 
defines the strain at which the straight line descent begins tension and compression $\left(x_{p}\right.$ and $\left.x_{n}\right)$ and parameter that controls the nonlinear descending branch (r) [14]. Tensile strain at the max tensile strength of concrete $\left(\varepsilon_{t}\right)$ was ignored at this modelling but the value was defined with 0.1 to assure the convergence of step by step analysis. The effect of confinement reinforcement was not considered for the core of the concrete, because the PHC pile is a hollow section and it has a small confinement reinforcement ratio. These concrete material input parameters are shown in Table 1.

Outside of plastic hinge zone of PHC pile model, Elastic Material was used to construct the elastic behavior of fiber section [10]. The input parameter of Elastic Material is the modulus elastic of the concrete and the damping tangent.

\subsection{Steel material parameter}

Steel02 material based on Giuffre-Menegotto-Pinto model was adopted to seimulate the behavior of the PC bar. The input parameters were yield strength $\left(f_{y}\right)$, initial elastic tangent $\left(E_{0}\right)$, strain-hardening ratio $(b)$ and the parameters to control the transition from elastic to plastic branches $\left(R_{0}, c R_{1}, c R_{2}\right)$ [10]. Table 1 summarize these steel material input parameters. To determine the PC bar pretensioning effect with magnitude $1101 \mathrm{MPa}$, Initial Strain material of OpenSees was adopted.

Table 1. Concrete07 and Steel02 parameter for the PHC piles model of Irawan's et al experiment [7]

\begin{tabular}{|l|l|l|l|}
\hline \multicolumn{2}{|c|}{ Concrete07 } & \multicolumn{2}{c|}{ Steel02 } \\
\hline$f_{c}^{\prime}(\mathrm{MPa})$ & 52.00 & $f_{y}(\mathrm{MPa})$ & 1387.00 \\
\hline$\varepsilon_{c}$ & 0.00233 & $E_{0}(\mathrm{MPa})$ & 220200.00 \\
\hline$E_{c}(\mathrm{MPa})$ & 36084.04 & $b$ & 0.05 \\
\hline$\varepsilon_{t}$ & 0.000248 & $R_{0}$ & 10 \\
\hline$x_{p}$ & 2 & $c R_{I}$ & 0.925 \\
\hline$x_{n}$ & 2.3 & $c R_{2}$ & 0.15 \\
\hline$R$ & 8.1 & & \\
\hline
\end{tabular}

\subsection{Results}

Based on the numerical analysis, the load-displacement curves analysed by OpenSees compared to the curves

\section{Numerical Analysis under Cyclic Loading}

\subsection{Structure idealization}

PHC piles tested under cyclic loading by Irawan et al [8] and Taksinrote [9] were simulated and analysed numerically using OpenSees. Piles were subjected to the compression axial and reserve lateral load. The axial loads of each specimen can be seen in Table 3. Summary of the actual displacement levels in cyclic loading used for each specimen are listed in Table 4. obtained from the experiment are shown in Fig. 11. The displacements were monitored at the middle of the pile model i.e. node 7 . Under monotonic loading, the initial stiffness and the yielding strength of PHC pile model calculated by OpenSees have good agreement with the experimental result, while the yielding and the ultimate strength of numerical model lower than the experimental result. Probably, the experimental PHC pile concrete material might have larger compressive strength than the mentioned in the reference [9]. Table 2 shows the comparison of the yield and ultimate capacity between experimental and numerical result. The error relative of both the yielding and the ultimate strength are around $12,5 \%$.

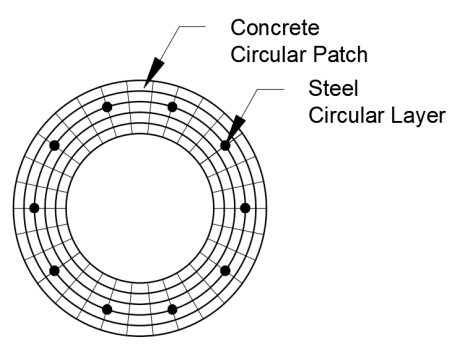

Fig. 10. Fiber section for PHC pile idealization model

Table 2. Yield and Ultimate Capacity of Irawan's et al Pile Specimen under Monotonic Loading

\begin{tabular}{|c|c|c|c|c|}
\hline \multirow{2}{*}{ Specimen } & \multicolumn{2}{|c|}{$\begin{array}{c}\text { Yield Capacity } \\
\text { (MPa) }\end{array}$} & $\begin{array}{c}\text { Ultimate Capacity } \\
\text { (MPa) }\end{array}$ \\
\cline { 2 - 5 } & Expr. & Num. & Expr. & Num. \\
\hline 1 & 136 & 120 & 164 & 140 \\
\hline 2 & 124 & 120 & 152 & 140 \\
\hline 3 & 128 & 120 & 160 & 140 \\
\hline
\end{tabular}

The extreme material strains of fiber section were monitored with the strain-displacement curves of the concrete and PC bars. Fig. 12 and Fig 13 show that the strain-displacement curves of steel and concrete material calculated by OpenSees have a good agreement with the experimental results. Based on this observation, the curvature occurrence of fiber section on plastic hinge area was fit with the experimental study.

Piles tested by Irawan et al [8] were S-TB-1 and STB-3 specimens. The piles were idealized as a frame element in the 2D model with 3 degrees of freedom. The model consisted of six nodes (one of them was dummy nodes) and four elements. Nodes and elements tags can be seen in Fig.14. Node 2 and 4 had equal DOF with node 6 . Forced-based beam-column element with fiber section is applied to all elements of the model. Element 2 and 3 were defined with non-linear fiber section and the other elements with linear elastic fiber section. The circular concrete patch was divided to 72 and 20 fibers in the circumferential direction and the radial direction respectively. 


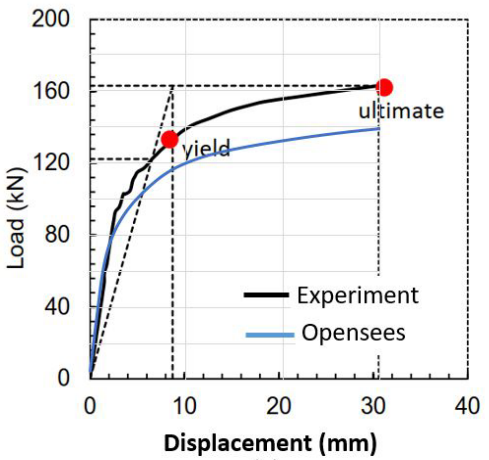

(a)

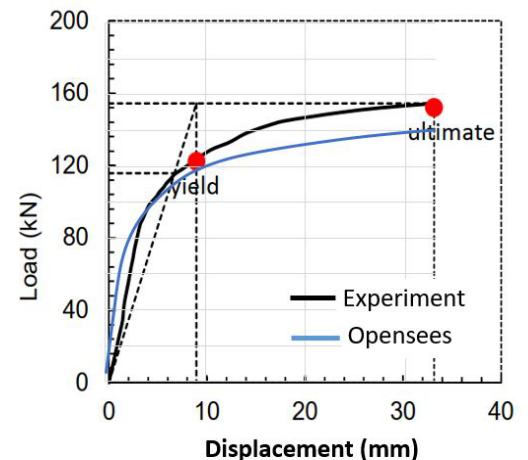

(b)

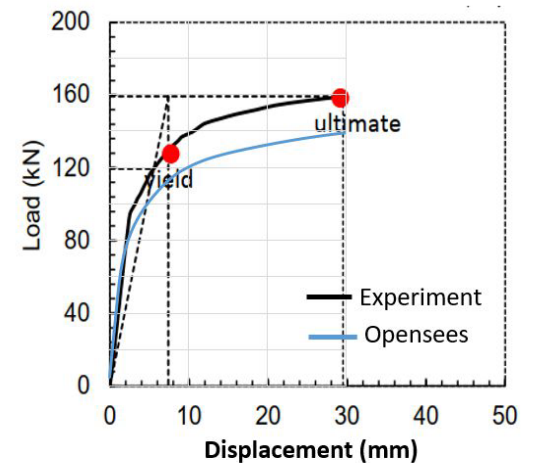

(c)

Fig. 11. Load - displacement curves (Monotonic Flexural Loading): (a) Specimen 1, (b) Specimen 2, and (c) Specimen 3

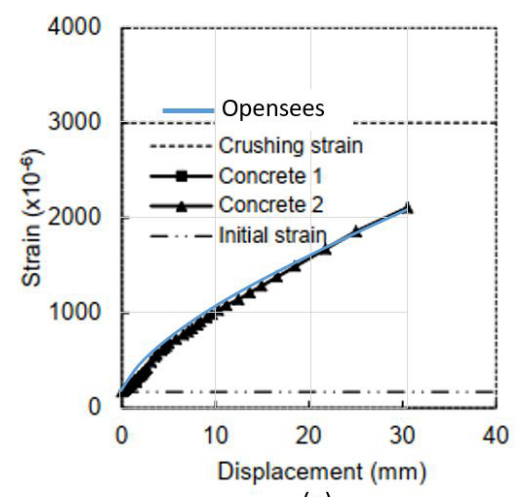

(a)

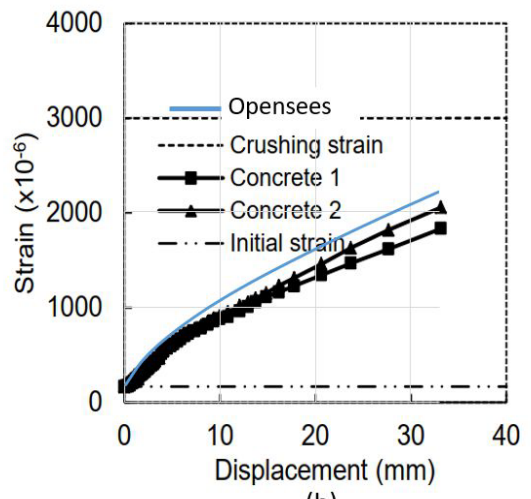

(b)

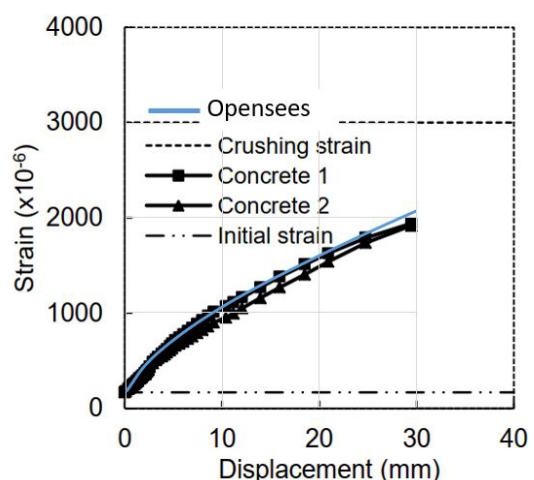

(c)

Fig. 12. Strain-displacement curves of concrete material (Monotonic Flexural Loading): (a) Specimen 1, (b) Specimen 2, and (c) Specimen 3

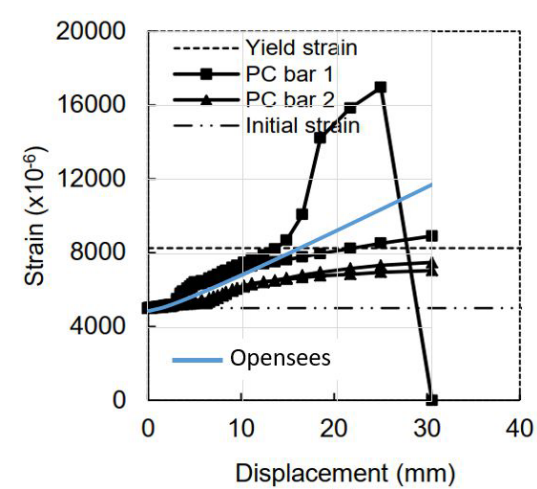

(a)

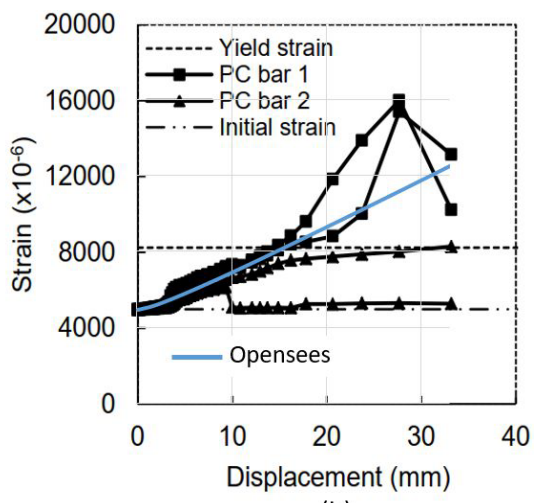

(b)

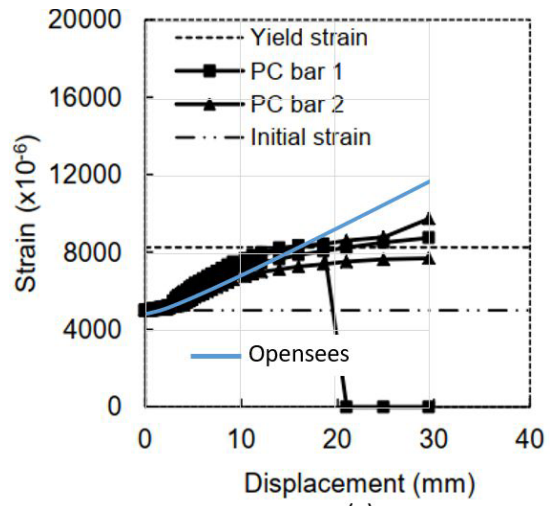

(c)

Fig. 13. Strain-displacement curves of steel material (Monotonic Flexural Loading): (a) Specimen 1, (b) Specimen 2, and (c) Specimen 3

While the piles tested by Taksinrote [9] due to cyclic lateral loading were P12A, P12B and P12D specimens. The piles were idealized as a frame element in the $2 \mathrm{D}$ model with 3 degrees of freedom. The model consisted of two nodes and an element. Nodes and element tags can be seen in Fig.15. Forced-based beam-column element with fiber section is applied to all elements of the model. Element 1 was defined with the non-linear fiber section and the other elements with linear elastic fiber section. The circular concrete patch was divided to
36 and 10 fibers in the circumferential direction and the radial direction respectively.

Modified two-point Gauss-Radau integration was used to define the hinge region in both simulations. Plastic hinge length defined in the PHC pile model of Irawan et al [8] experiment was $560 \mathrm{~mm}$ following the experimental of Budek [5]. 3D plastic hinge length was defined to the PHC pile model idealization for Taksinrote's experiment, following the plastic hinge length obtained by Cofer et al using ABAQUS finite element simulation of hollow prestressed pile [15]. 


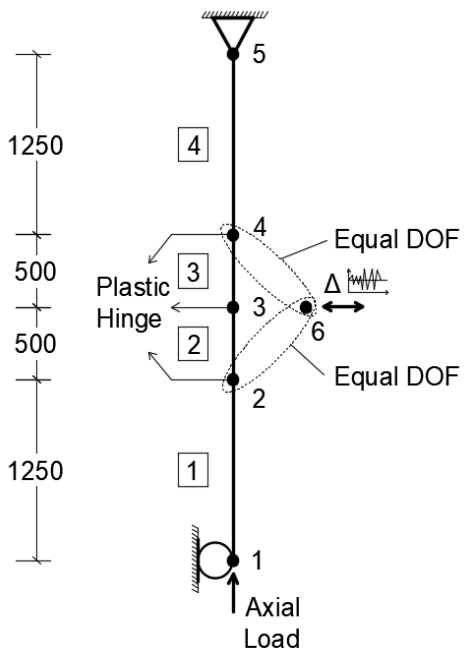

Fig. 14. PHC Pile model idealization for Irawan's et al experiment [8]

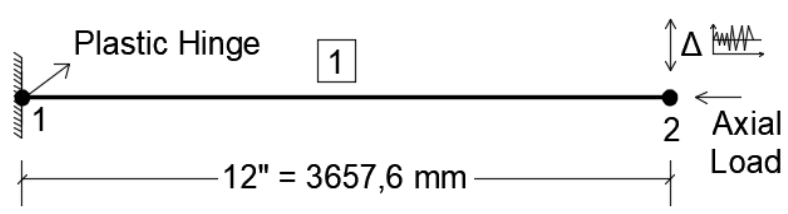

Fig. 15. PHC Pile model idealization for Taksinrote's experiment [9]

Table 3. Axial loads subjected to each pile specimens

\begin{tabular}{|c|c|}
\hline Specimen & Axial Load (kN) \\
\hline S-TB-1 & 400 \\
\hline S-TB-3 & 800 \\
\hline P12A & 0 \\
\hline P12B & 200 \\
\hline P12D & 100 \\
\hline
\end{tabular}

Table 4. Displacement control for cyclic loading

\begin{tabular}{|c|c|}
\hline Specimen & Displacement level (mm) \\
\hline S-TB-1 & $20,40,60.100,120,140,307,385,482$ and \\
S-TB-3 & 613 \\
\hline P12A & $10,20,30,40,60,80,100,120$ and 140 \\
\hline P12B & $20,40,60.100,80,120$ and 140 \\
P12D & \\
\hline
\end{tabular}

\subsection{Concrete material parameter}

Table 5. Concrete 07 material parameter for the model idealization of the pile tested due to cyclic lateral loading

\begin{tabular}{|l|c|c|c|c|}
\hline & $\begin{array}{c}\text { S-TB-1 } \\
\text { S-TB-3 }\end{array}$ & P12A & P12B & P12D \\
\hline$f_{c}{ }^{\prime}$ & 54.4 & 78.8 & 82.2 & 79.1 \\
\hline$\varepsilon_{c}$ & 0.0024 & 0.0026 & 0.0026 & 0.00259 \\
\hline$E_{c}$ & 36699.78 & 42170.74 & 42844.08 & 42230.87 \\
\hline$\varepsilon_{t}$ & 0.000249 & 0.000261 & 0.000262 & 0.000261 \\
\hline$x_{p}$ & 2 & 2 & 2 & 2 \\
\hline$x_{n}$ & 2.3 & 2.3 & 2.3 & 2.3 \\
\hline$r$ & 8.56 & 13.25 & 13.91 & 13.31 \\
\hline
\end{tabular}

Concrete07 material of OpenSees as mentioned at subsection 3.2 was implemented to model the concrete of the pile tested by Irawan et al [8] and Taksinrote [9].
Concrete07 material input parameters used in the simulation of the piles are listed at Table 5. Tensile strain at the max tensile strength of concrete $\left(\varepsilon_{t}\right)$ was ignored at this modelling but the value was defined with 0.1 so that the algorithm still could be run.

\subsection{Steel material parameter}

The PC bars material utilized the Steel02 material mentioned in subsection 3.3. Steel02 material input parameters used in the simulation of the piles tested by Irawan et al [8] and Taksinrote [9] are shown in Table 6. Initial stress material of OpenSees utilized to define the initial strain of the PC bar was $1101 \mathrm{MPa}$ and $1065 \mathrm{MPa}$ $\left(75 \% f_{u}\right)$ in modelling of piles tested by Irawan et al [8] and Taksinrote [9] respectively.

Table 6. Steel02 material parameter for the model idealization of the pile tested due to cyclic lateral loading

\begin{tabular}{|l|c|c|}
\hline Specimen & S-TB-1. S-TB-3 & P12A, P12B, P12D \\
\hline$f_{y}(\mathrm{MPa})$ & 1387 & 1395 \\
\hline$E_{0}(\mathrm{MPa})$ & 220267 & 199100 \\
\hline$b$ & 0.05 & 0.05 \\
\hline$R_{0}$ & 10 & 10 \\
\hline$c R_{I}$ & 0.925 & 0.925 \\
\hline$c R_{2}$ & 0.15 & 0.15 \\
\hline
\end{tabular}

\subsection{Results}

The load-displacement curves obtained from the experiment compared to the curves calculated by OpenSees are shown in Fig. 16 and Fig. 17. The loaddisplacement curves calculated by OpenSees agreed well with the experimental results conducted by Irawan et al [8] and Taksinrote [9]. However, the strength degradation behaviour of the reference's [8] experimental could not be simulated due to unconsidering the effect flexural-shear failure. Table 7 summarizes the maximum lateral force obtained from the numerical analysis of both Irawan's et al and Taksinrote's experiment. It indicates that increasing the axial load can increase the lateral force occurred.

Table 7. Maximum lateral force of the PHC piles

\begin{tabular}{|c|c|}
\hline Specimen & Lateral Force $(\mathbf{k N})$ \\
\hline S-TB-1 & 221.361 \\
\hline S-TB-3 & 268.221 \\
\hline P12A & 12.263 \\
\hline P12B & 17.295 \\
\hline P12D & 15.027 \\
\hline
\end{tabular}

Each equal damping curves were put on the right of the hysteresis loops in Fig. 16 and Fig. 17. The pinching hysteresis loops and low displacement ductility in all PHC pile of specimens were observe. It can be observed that hysteretic curve of specimen P12A of Taksinrote's experiment is plumper compared with the other specimens. The equal damping ratio of the numerical model that was calculated with Jacobsen's Approach were expressed by Equation 1. $A_{\text {hysr }}$ is the energy dissipation area of the hyterisis loop in a cycle loading then $A_{0}$ is the twice area of elastic strain energy. The 
equal damping curves show that the spun has a low damping (below 10\%) and the greater axial force aplied to the PHC pile result the lower equal damping.
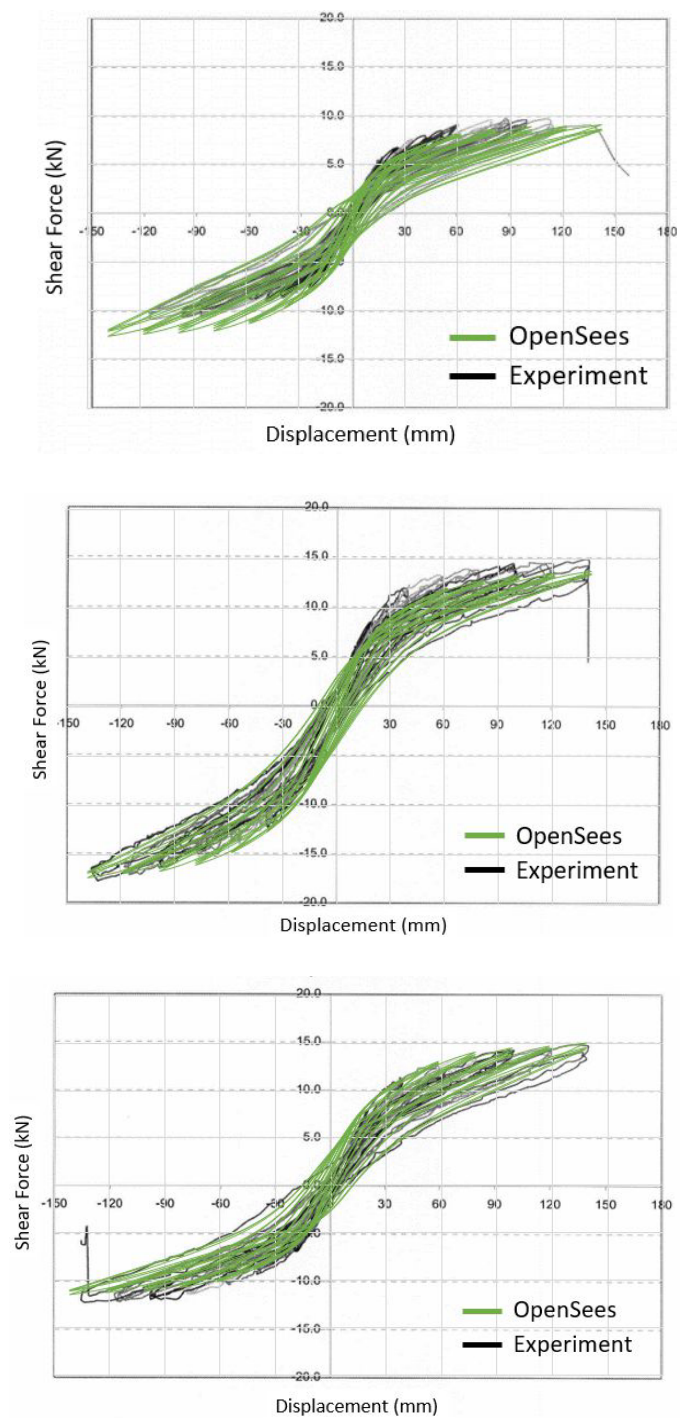

Fig. 16. Load-displacement curves of PHC Pile model simulation for Taksinrote's et al experiment: (a) P12A, (b) P12B, (c)

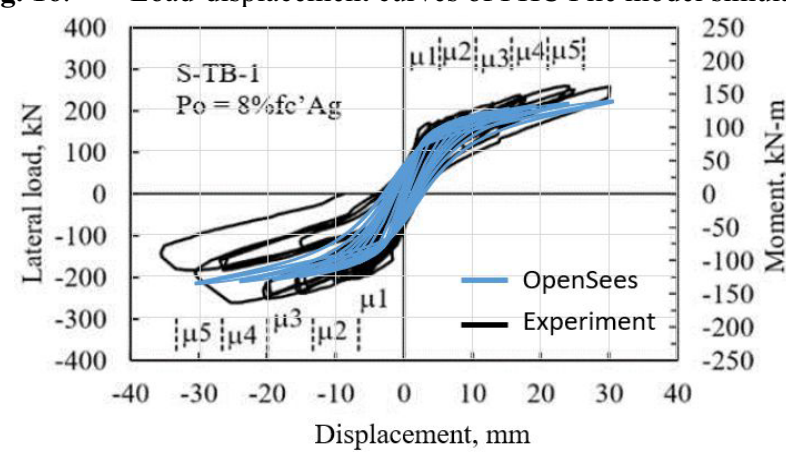

(a)

$$
\zeta=\frac{1}{2 \pi} \frac{A_{\text {hyst }}}{A_{0}}
$$

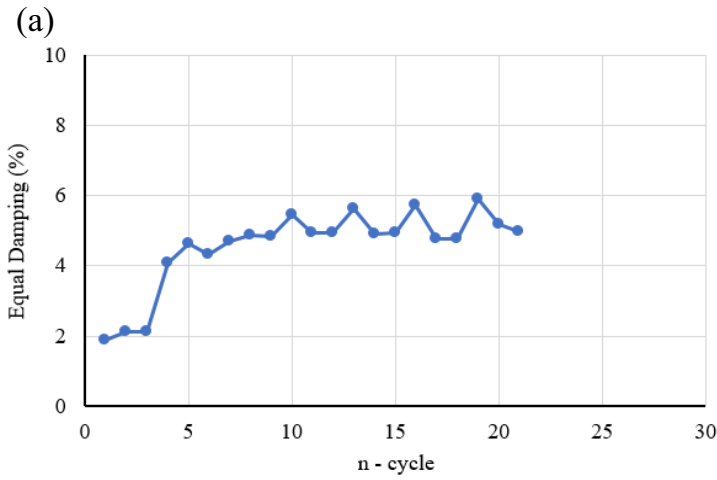

(b)

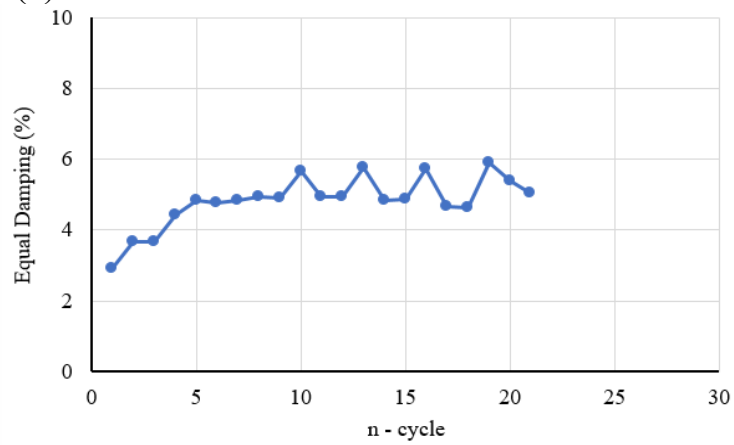

(c)

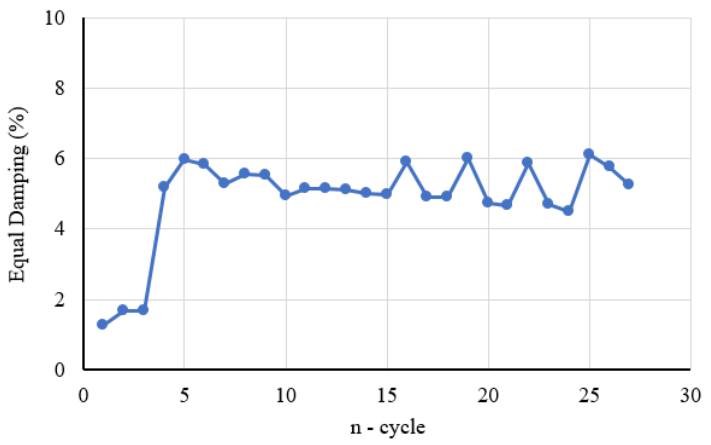

(a)

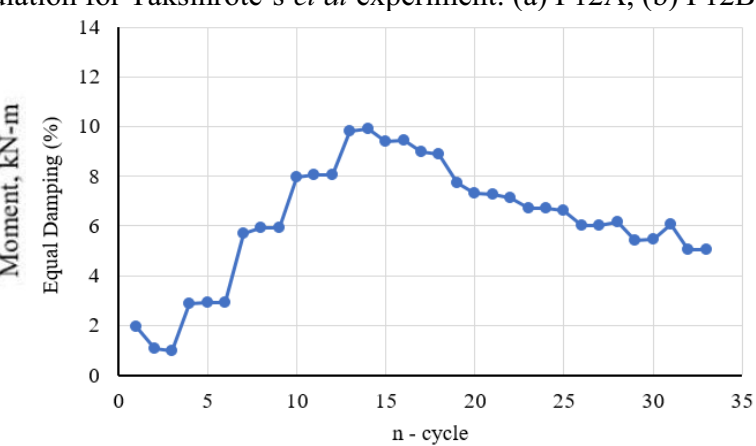




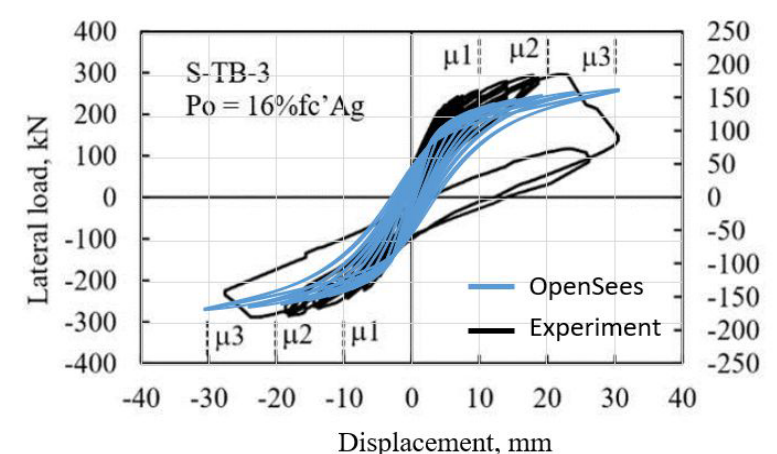

(b)

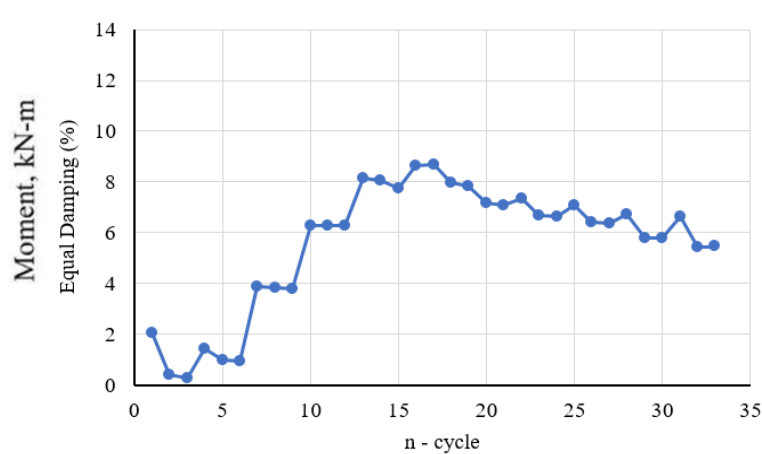

Fig. 17. Load-displacement and equal damping curves of PHC Pile model simulation for Irawan's et al experiment: (a) S-TB-1 Specimen, (b) S-TB-3 Specimen

\section{Conclusions}

Based on the numerical simulation of experimental studies PHC piles using OpenSees, the main results can be summarized as follows:

1. By using initial strain command section in Opensees, the effect of prestressing bar to the PHC pile behaviour could be simulated by using force-based beam-column with hinges element with fiber.

2. Under monotonic loading, initial stiffness and yielding strength of PHC pile model have sufficient agreement with the experimental result, while the ultimate strength of numerical model lower than the experimental result. The experimental PHC pile concrete material might have larger compressive strength than the mentioned in the reference [7]. Furthermore, the strain of the PC bars and concrete compression fibers had good agreement.

3. Under cyclic loading, the initial stiffness, the yield strength, post-yeld stiffness of PHC pile model have good agreement with the experimental results of the references [8] and [9]. However, the strength degradation behaviour of the reference's [8] experimental could not be simulated due to the effect flexural-shear failure. While the numerical model only considering flexural failure.

4. The addition of axial load to the PHC pile can increase the amount of lateral force occured.

5. Even though PHC pile could achieve ductility around 3, it just only reaches a low energy dissipation (equal damping ratio below 10\%).

6. With the good agreement results of the numerical simulation, the numerical model of PHC pile with fiber section could be adopted for the structural simulation of PSSV under seismic load.

\section{Recommendations}

To accomplish the PHC numerical model which will be built for pile-supported slab viaduct (PSSV) structure, shear-flexural failure model of $\mathrm{PCH}$ pile need to be developed.

The author gratefully acknowledge to Department of Civil and Engineering, Universitas Gadjah Mada and PT Wijaya Karya Beton that had funded this research.

\section{References}

1. Asrurifak, Peta Gempa Indonesia 2017 dan Aplikasinya Untuk Perencanaan Struktur Gedung dan Infrastruktur Tahan Gempa, ITS Surabaya, (2017)

2. Y. Pusparisa, Gempa \& Tsunami Terbesar Indonesia dalam 20 Tahun,

https://katadata.co.id/infografik/2019/07/30/gempadan-tsunami-terdahsyat-di-indonesia-selama-duadekade

3. https://id.wikipedia.org/wiki/Gempa_bumi_Halmah era 2019

4. H. Indarto, Evaluasi Kekuatan Struktur Slab on Pile pada Pembangunan Ruas Jalan SebelimbinganMartadipura Kota Bangun, Kutai Kertanegara, Kalimantan Timur (2015)

5. A. M. Budek and M. J. N. Priestley, Coast. Eng. J., 47 (1), 1-20 (2005)

6. A. F. Setiawan, Y. Takahashi, J. Kiyono, and S. Sawada, Procedia Eng.171, 821-835 (2017)

7. C. Irawan, R. Djamaluddin, I. G. P. Raka, and P. Suprobo, the International Conference on Protective Structures (ICPS4), Beijing, China (2016)

8. C. Irawan, R. Djamaluddin, I. G. Putu Raka, Faimun, P. Suprobo, and - Gambiro, Int. J. Adv. Sci. Eng. Inf. Technol. 8 (2) (2018)

9. W. Taksinrote, Seismic performance of pretensioned spun high strength concrete piles, The University of British Columbia (2001)

10. S. Mazzoni, F. McKenna, M. H. Scott, and G. L. Fenves, OpenSees Command Language Manual (2007)

11. M. H. Scott, Numerical Integration Options for the Force-Based Beam-Column Element in OpenSees 
12. A. M. Budek, G. Benzoni, and M. J. N. Prestley, Experimental Investigation of Ductility of InGround Hinges in Solid and Hollow Prestressed Piles, University of California, San Diego (1997)

13. G. A. Chang and J. B. Mander,

http://opensees.berkeley.edu/wiki/index.php/Concret
e07_\%E2\%80\%93_Chang_\%26_Mander\%E2\%80 $\% 99$ s 1994_Concrete_Model

14. W. F. Cofer, M. ElGawady, and S. M. Greenwood, Seismic Assessment of WSDOT Bridges with Prestressed Hollow Core Piles - Part 1 